Review

\title{
Small Engine, Big Power: MicroRNAs as Regulators of Cardiac Diseases and Regeneration
}

\section{Darukeshwara Joladarashi, Rajarajan Amirthalingam Thandavarayan, Sahana Suresh Babu and Prasanna Krishnamurthy *}

Department of Cardiovascular Sciences, Centre for Cardiovascular Regeneration, Houston Methodist Research Institute, Houston, TX 77030, USA;

E-Mails: djoladarashi@houstonmethodist.org (D.J.); ramirthalingamthandavarayan@houstonmethodist.org (R.A.T.); ssureshbabu@houstonmethodist.org (S.S.B.)

* Author to whom correspondence should be addressed;

E-Mail: pkrishnamurthy@houstonmethodist.org;

Tel.: +1-713-363-8080; Fax: +1-713-793-7162.

Received: 11 July 2014; in revised form: 27 August 2014 / Accepted: 27 August 2014 /

Published: 9 September 2014

\begin{abstract}
Cardiac diseases are the predominant cause of human mortality in the United States and around the world. MicroRNAs (miRNAs) are small non-coding RNAs that have been shown to modulate a wide range of biological functions under various pathophysiological conditions. miRNAs alter target expression by post-transcriptional regulation of gene expression. Numerous studies have implicated specific miRNAs in cardiovascular development, pathology, regeneration and repair. These observations suggest that miRNAs are potential therapeutic targets to prevent or treat cardiovascular diseases. This review focuses on the emerging role of miRNAs in cardiac development, pathogenesis of cardiovascular diseases, cardiac regeneration and stem cell-mediated cardiac repair. We also discuss the novel diagnostic and therapeutic potential of these miRNAs and their targets in patients with cardiac diseases.
\end{abstract}

Keywords: miRNA; cardiac development; cardiovascular diseases; hypertrophy; fibrosis; arrhythmia; cardiac regeneration; stem cells 


\section{Introduction}

Heart disease is the number one cause of death for both men and women in the United States [1]. By 2030, heart disease will be the leading cause of death throughout the world [2,3]. Sixteen out of eighty million U.S. adults affected with cardiovascular diseases carry the diagnosis of coronary artery disease. Ischemic injury due to coronary artery disease results in permanent loss of cardiac tissue leading to adverse cardiac remodeling process and diminished contractility contributing to heart failure. At the cellular level, heart failure is associated with a decrease in cardiomyocyte and endothelial cell viability, hypertrophy of existing myocytes, inflammation, mitochondrial dysfunction (altered energetics and reactive oxygen species production), cardiac fibrosis, arrhythmia and vascular defects. At the molecular level, heart development and diseases are controlled by various gene regulatory networks including transcription factors, co-activators and repressors, their corresponding enhancer and promoter elements and chromatin-modifying enzymes.

MicroRNAs (miRNAs) constitute a growing class of non-coding small RNAs, 20-25 nucleotides in length that act as molecular switches of gene expression and are thought to regulate complex cardiac signaling and transcriptional circuits during cardiac development and disease [4-6]. miRNAs have been shown to exhibit developmental-stage-specific or tissue-specific expression, suggesting that they might play important roles in many biological processes [7]. Indeed, miRNAs are known to regulate different cellular processes such as proliferation, differentiation, cell metabolism, apoptosis and angiogenesis [8-16]. Mechanistically, miRNAs regulate gene expression on the post-transcriptional level by inhibiting the translation of protein from mRNA or by promoting the degradation of mRNA. In the present review, we provide an overview of recent studies highlighting the important role of miRNAs in cardiovascular development and diseases, as well as their potential use for diagnosis, prevention, and treatment of cardiovascular diseases.

\section{Biogenesis of miRNA and Its Target Sites}

The first identified miRNA, lin-4 was discovered in 1993 and was shown to control developmental timing in Caenorhabditis elegans by suppressing lin-14 protein expression [17,18]. In humans, more than $60 \%$ of all protein-coding genes appear to be conserved miRNA targets [19,20]. Most mammalian primary-miRNAs (pri-miRNA) are transcribed by RNA polymerase II as long precursor molecules containing stem-loop structures (approximately $10 \mathrm{~kb}$ in length) [21,22]. Following transcription of pri-miRNA in the nucleus, microprocessor complex containing Drosha (RNase III endonuclease) and RNA-binding protein, DGCR8 (DiGeorge syndrome critical region 8) mediate the processing of the pri-miRNA into precursor-miRNAs (pre-miRNA, 70 nucleotide hairpin-structures) [23]. The pre-miRNA is exported from nucleus to the cytoplasm (by exportin-5 in a Ran-GTP dependent manner), where it is cleaved by another RNase III endonuclease, Dicer, into mature miRNA ( 22-25 nucleotide RNA duplex). This RNA is subsequently unwound by a helicase activity, binds to an Argonaute protein and gets incorporated as single-stranded RNA into the RNA-induced silencing complex (RISC) [24], which directs the miRNA to complementary sites within the 3' UTRs (untranslated region) of target mRNAs leading to translational repression or degradation of the target mRNA [23,25]. Interestingly, miRNAs can act as translational activators as well [26]. Based on 
computational algorithms, around $60 \%$ of human transcripts contain potential miRNA-binding sites within their 3' UTRs [20]. A "seed sequence" in the 5' end of the mature miRNA pairs to nucleotides 2 through 8 at the 3' UTR of target mRNAs [23]. However, miRNAs can interact with 5' UTRs, protein-coding sequences and introns [27]. Furthermore, miRNAs can also localize to the nucleus, where they may regulate transcription/splicing of transcripts, or serve as signaling molecules between two cells through exosome transfer [28]. Although a single miRNA can target many genes, it is possible that multiple miRNAs can regulate a single gene $[25,29,30]$. These studies suggest that miRNA transcription to maturation involves several coordinated steps and that deregulation in miRNA biogenesis and function might contribute to the development of cardiovascular diseases [31,32].

\section{Role of miRNAs in Cardiac Development and Diseases}

\section{1. miRNAs in Cardiac Development}

During embryogenesis, the heart is the first organ to form and disruption in its development and function results in a variety of congenital disorders [32,33]. The developing heart undergoes a series of transformations resulting in the formation of a multi-chambered heart. Cardiomyocytes play an important role in the growth of the heart prior to birth. The post-natal heart growth is attained mainly through cellular hypertrophy [34,35]. Heart development involves precise and complex interactions and regulation of signaling molecules among diverse cell types from several lineages including: cardiomyocytes, endocardial, epicardial and vascular cells, fibroblasts and cells of the conduction system [36-40]. The role of miRNAs as a critical regulator of biological processes in embryonic, postnatal, and adult hearts is beginning to evolve.

Cardiac cells contain specific types of miRNA and it was found that only a particular miRNA participates in the specification of cell identity. The expression of miRNA-1 and miRNA-133a is cardiac and skeletal-muscle specific. Zhao et al. (2007) [31] showed that miRNA biogenesis in the mouse heart is essential for cardiogenesis and that targeted deletion of muscle-specific miRNA, miRNA-1-2, revealed numerous functions in the heart, including regulation of cardiac growth and differentiation, electrical conduction, and cell-cycle control through modulation of transcription factors like Irx4, Hrt2, Hand1 and Gata6. Furthermore, miRNA-1 and miRNA-133 genes are direct transcriptional targets of muscle differentiation regulators including serum response factor, MyoD or Mef2, suggesting a common set of regulatory elements that control cardiac and skeletal muscle development [41,42].

Dicer, an endoribonuclease of the RNase III family, is involved in the maturation of most miRNAs, and therefore might have significant impact on several biological processes. Dicer has been shown to be required for normal skeletal muscle development [40]. Interestingly, cardiac-specific deletion of Dicer results in defective heart development and embryonic lethality [31]. Similarly, Drosha/Dgcr8 containing complex also plays a role in miRNA processing. Cardiomyocyte-specific deletion of $d g c r 8$, a gene required for microRNA biogenesis, revealed left ventricular malfunction progressing to a dilated cardiomyopathy and premature lethality, therefore, further highlighting the importance of miRNAs in heart development and function [32]. 
miRNA-133a negatively regulates cardiomyocyte proliferation during heart development. Over-expression of miRNA-133a driven by the $\beta$ MHC promoter in embryonic cardiomyocytes inhibits cardiomyocyte proliferation and causes embryonic lethality characterized by a thinner ventricular wall [43]. On the contrary, miRNA-133a mutant mice exhibit excessive cardiomyocyte proliferation, attributed, in part, due to elevated expression of SRF and cyclin D2, which are targets for repression by miRNA-133a [43]. In another interesting study, hearts of miRNA-17-92-deficient mouse embryos presented a clear ventricular septal defect and severely hypoplastic lungs, suggesting critical roles for the miRNA-17-92 cluster during heart development [44]. Recent analysis identified miRNAs expressed in undifferentiated mouse embryonic stem cells and differentiating cardiomyocytes and found increased level of miRNA-1, miRNA-18, miRNA-20, miRNA-23b, miRNA-24, miRNA-26a, miRNA-30c, miRNA-133, miRNA-143, miRNA-182, miRNA-183, miRNA-200a/b, miRNA-292-3p, miRNA-293, miRNA-295 and miRNA-335 in mice [14,45]. Thus, miRNAs appear to play important roles in orchestrating organogenesis and early embryonic patterning processes.

Understanding the mechanisms of heart development may provide novel information for cardiac reprogramming technology therefore promoting newer therapeutic approaches for heart disease in the future.

\section{2. miRNAs in Cardiac Hypertrophy}

Cardiac hypertrophy is defined as enlargement, or thickening of the interventricular wall and/or septum, resulting from increases in cardiomyocyte size and changes in heart muscle signaling components [46-52]. Physiological hypertrophy is growth of heart, in response to exercise training or physiological needs like postnatal development and pregnancy, and an adaptive response that leads to stimulation of cardioprotective signaling cascades. In contrast, heart enlargement in response to cardiovascular diseases is broadly referred to as pathological hypertrophy and often progresses to heart failure [53].

To demonstrate the role of miRNAs in physiological hypertrophy in humans, Mooren et al. (2014) [54] investigated heart/muscle specific and inflammation related miRNAs in plasma of individuals before, directly after, and $24 \mathrm{~h}$ after a marathon run and correlated their relation to conventional biochemical, cardiovascular, and performance indexes. Interestingly, muscle specific miRNA, miRNA-1 showed a moderate negative correlation with fractional shortening, whereas miR-133a was positively related to the thickness of the intraventricular septal wall [54].

Intriguingly, analysis of the global expression of microRNAs in an experimental model of physiological left ventricular hypertrophy in mice showed an increase in miR-150 levels after 35 days and a decrease in miRNA-26b, miRNA-27a and miRNA-143 after 7 days of voluntary exercise [55]. Furthermore, the authors show that previously established regulatory gene pathways involved in pathological left ventricular hypertrophy are not changed in physiological left ventricular hypertrophy [55]. These studies suggest that understanding the role of miRNA in physiological hypertrophy might provide novel information that could be used to reverse the pathological hypertrophy process.

Studies using arrays to determine global expression of miRNAs have shown that pathological cardiac hypertrophy modulates miRNA expression [45,56-62]. These studies indicate that miRNAs, 
miRNA-208, miRNA-23a, miRNA-24, miRNA-125, miRNA-21, miRNA-129, miRNA-195, miRNA-199, and miRNA-212 are frequently increased in response to cardiac hypertrophy, whereas, miRNA-29, miRNA-1, miRNA-30, miRNA-133, and miRNA-150 expression are often found to be decreased. Therefore, forced expression of individual miRNAs for example miRNA-195 was sufficient to exacerbate pathological cardiac hypertrophy when over expressed in transgenic mice [16]. miR-195 targets mouse protein-25 (MO25), a central component of the MO25/Ste20 Related Adaptor (STRAD)/liver kinase B1 (LKB1) complex that acts as an upstream kinase for adenosine monophosphate-activated kinase (AMPK), a prominent player in the development of cardiac hypertrophy and heart failure [63]. In another study, in vitro over-expression of miRNA-150 and miRNA-181b, which are down-regulated in cardiac hypertrophy, resulted in reduced cardiomyocyte cell size [57]. Also, transgenic over-expression of miR-208a in the heart was sufficient to induce hypertrophic growth in mice, which resulted in pronounced repression of the miR-208 regulatory target thyroid hormone-associated protein 1 and myostatin, two negative regulators of muscle growth and hypertrophy [56]. Interestingly, suppression of miRNA-208a in heart failure rats prevents the pathological myosin switching while improving cardiac function [64]. Recent study has shown that pharmacological inhibition of miR-21 in a mouse model of Ang II-induced cardiac hypertrophy attenuated pathology [65]. These findings demonstrate an important role for specific miRNAs in the control of hypertrophic growth and remodeling of the heart in response to pathological signaling; therefore indicating that miRNAs might be targeted for therapy against heart disease.

\section{3. miRNAs in Cardiac Fibrosis}

Cardiac fibrosis is characterized by inappropriate deposition of extracellular matrix proteins in the myocardium leading to increased ventricular stiffness and contractile dysfunction, important contributors for the progression of heart failure in various pathophysiological conditions [46-49,51,52,66-74]. In addition, fibrosis causes disruption in electrical conductivity between cardiac myocytes, and therefore increasing susceptibility to arrhythmias $[68,69,75]$.

Studies have shown that miRNA-21 is one of the most strongly up-regulated miRNAs in response to various forms of stress $[16,57,76]$. To demonstrate the role of miRNAs in cardiac fibrosis, Thum et al. (2008) has shown that miRNA-21 is up-regulated in cardiac fibroblasts in the failing heart and it represses the expression of Sprouty homologue 1 (Spry1) [77]. Furthermore, increased miRNA-21 augments extracellular signal-regulated kinase/mitogen-activated protein kinase signaling [77] or increased MMP-2 expression via decreased phosphatase and tensin homologue (PTEN) [78], leading to fibroblast proliferation and fibrosis. Intriguingly, cardiac fibroblasts have been shown to secrete miRNA-21-enriched exosomes that mediates cardiomyocyte hypertrophy through a paracrine signaling mechanism [65].

In our recent study, we demonstrated that miRNA-155 regulates cardiac fibrosis in diabetic $(d b / d b)$ mice, possibly via inhibition of anti-fibrotic Sloan-Kettering Institute proto-oncogene (Ski) and Ski-related novel gene, non-Alu-containing ( $\mathrm{SnoN}$ ) signaling (negative regulators of TGF- $\beta$ signaling) [6]. In another study, Duisters et al. (2009) [79] has demonstrated that miRNA-133 and miRNA-30, both consistently down regulated in several models of pathological hypertrophy and heart failure, regulate connective tissue growth factor (CTGF), a key molecule involved in fibrosis. 
Furthermore, in vitro experiments designed to modulate these miRNAs has been shown to effectively regulate CTGF expression by interacting directly with the 3' UTR region of CTGF mRNA [79].

Also, it has been shown that miR-29 family is down-regulated in the region of the heart adjacent to the infarct. The miR-29 family targets mRNAs that encode extracellular matrix-related proteins like collagens, fibrillins, and elastin, proteins involved in fibrosis [16]. Furthermore, down-regulation of miR-29 with anti-miRs in vitro and in vivo induced the expression of collagens [16]. These investigations indicate that miRNAs are important modulators of cardiac fibrosis and are involved in structural alteration during the progression of heart disease.

\section{4. miRNAs in Cardiac Arrhythmias}

Ischemic heart disease is a form of congestive heart failure that is caused by insufficient blood supply to the heart, resulting in loss of viable tissue. In response to injury, the non-ischemic myocardium displays signs of secondary remodeling, like interstitial fibrosis and hypertrophy. This remodeling process further deteriorates pump function and increases susceptibility to cardiac arrhythmias, in which the electrical activity of the heart is irregular resulting in significant morbidity and mortality. Muscle-specific miRNAs, miRNA-1 and miRNA-133 in addition to their role in cardiac development have been shown to be significantly up-regulated in ischaemic injury in the heart in both rodents and humans [75,80,81]. Over-expression of miRNA-1, in normal or infarcted rat hearts, slowed conduction and depolarized the cytoplasmic membrane by post-transcriptionally repressing KCNJ2 (which encodes the $\mathrm{K}^{+}$channel subunit Kir2.1) and GJA1 (which encodes connexin 43), and therefore exacerbates arrhythmogenesis [75]. Recent studies indicate that connexin 43, a major cardiac gap junction protein, is a direct target of miRNA-130a and that over-expression of miRNA-130a may contribute importantly to gap junction remodeling and to the pathogenesis of atrial and ventricular arrhythmias [82].

Clinical and preclinical studies have shown that miRNA-212 is up-regulated during heart failure [45,83,84]. miRNA-212 targets Kir2.1 (KCNJ2 mRNA) that carries an inward rectifier $\mathrm{K}^{+}$current critical for maintaining membrane potential. Studies have indicated that Pitx2 (homeobox transcription factor) insufficiency leads to atrial electrical and structural remodeling linked to arrhythmogenesis [85,86]. Intriguingly, Pitx2 has been shown to positively regulate miRNA-17-92 and miRNA-106b-25. Furthermore, intracardiac electrical stimulation revealed that both miRNA-17-92 and miRNA-106b-25 deficient mice exhibit pacing-induced atrial fibrillation, the most common sustained cardiac arrhythmia [87].

A recent study investigated the relation of reduced expression of miRNA-150 in platelets to atrial fibrillation in patients with chronic systolic heart failure. The authors concluded that miRNA-150 expression levels in platelets of patients with systolic heart failure with atrial fibrillation are significantly reduced and correlated to the cell-free circulating levels of this miRNA. However, the role of miRNA-150 in atrial fibrillation has not been completely understood [88]. Interestingly, in a rabbit model of diabetes, miRNA-133 was shown to be up-regulated in the heart in association with increased expression of serum response factor, which is known to be a transactivator of miRNA-133 [89]. The authors further show that miRNA-133 represses ERG (ether-a-go-go-related gene) leading to depressed $I_{\mathrm{Kr}}$, slow repolarization and QT prolongation associated with arrhythmias in diabetic hearts. 
Diabetic patients are at increased risk for heart failure [90]. A recent study has shown that hyperglycemia augmented expression of miRNA-1 and miRNA-133 in human cardiac progenitor cells associated with suppressed KCNE1 and KCNQ1 and significant reduction in the functional $I_{\mathrm{Ks}}$ current [91]. Furthermore, addition of miRNA-1 and miRNA-133 antagomirs diminished the

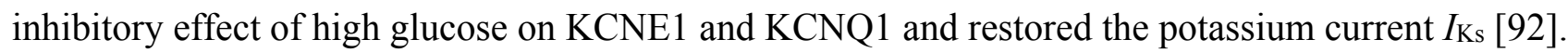

\section{5. miRNAs in Endothelial Homeostasis and Angiogenesis}

Endothelial cell integrity and function is fundamental for homoeostasis of the vascular system. The induction of new blood vessel formation is an orchestrated process, which is critical during development and tissue repair in response to injury. A recent study suggests that miRNA-26a regulates pathological and physiological angiogenesis by targeting endothelial cell (EC) bone morphogenic protein/SMAD1 signaling in vitro and in vivo [93]. Interestingly, systemic intravenous administration of a miRNA-26a inhibitor increased SMAD1 expression and rapidly induced angiogenesis associated with improved heart function [93]. Local delivery of adenovirus-mediated miRNA-24 decoy in the ischemic area of myocardium increased angiogenesis and blood perfusion [94]. Human endothelial cells from advanced neovascularized atherosclerotic lesions showed that miRNA-222 expression was negatively correlated to signal transducer and activator of transcription 5A (STAT5A) expression and diminished proliferation and vessel formation ability [95]. Knockdown of miRNA-221 and miRNA-222 suppressed vascular smooth muscle cell (VSMC) proliferation and neointimal lesion formation after carotid angioplasty [96]. miR-210 over-expression stimulates tubulogenesis and migration by targeting receptor tyrosine-kinase ligand Ephrin-A3 [92]. Chen and Gorski [97] showed that miRNA-130a regulates angiogenic phenotype of vascular ECs through down-regulation of anti-angiogenic homeobox genes GAX and HOXA5 [97]. Intriguingly, endothelial cell specific miRNA, miRNA-126-mediated phosphoinositide-3-kinase regulation stimulates VEGF-signaling and strongly enhances the activities of Ang-1 on vessel stabilization and maturation [98]. These studies suggest that regulating miRNAs involved in endothelial cell biology and function serves as potential therapeutic target to treat diseases with vascular dysfunction.

\section{4. miRNAs in Cardiac Regeneration and Stem Cell-Mediated Repair}

Coronary artery occlusion with cycles of ischemia and reperfusion leads to chronic inflammation and oxidative stress resulting in significant loss of cardiac myocytes and endothelial cells, causing impairment in cardiac function and heart failure. The existing therapies slow down the pathogenesis of cardiovascular diseases, however, the long-term survival of patients with heart failure depends on regenerating the lost cardiac tissue and reestablishing perfusion in the myocardium, therefore leading to improved repair of the heart tissue. In this direction, recent concepts for myocardial regeneration include: stimulating terminally differentiated cardiomyocyte to proliferate, stem/progenitor cell transplantation, direct reprogramming of scar tissue into functional myocardium and tissue engineering.

Shortly after birth, cardiomyocytes stop proliferating, therefore, their ability to regenerate in response to injury is very limited [99]. Intriguingly, recent evidences indicate that cardiomyocytes are able to proliferate during the postnatal life [100,101]. Porrello et al. [102] demonstrated that the miRNA-15 family of miRNAs modulates neonatal heart regeneration through inhibition of postnatal 
cardiomyocyte proliferation. Further analysis showed that miRNA-195 (a member of miRNA-15 family) regulates expression of a number of cell cycle genes, including checkpoint kinase 1 (Chek1), which was identified as a highly conserved direct target of miRNA-195 [102]. Most recently, using both transgenic and knockout mice models, Chen et al. (2013) [103] demonstrated that miRNA-17-92 cluster (specifically, through miRNA-19a/b-mediated inhibition of the tumor suppressor gene, PTEN) is required for and sufficient to induce cardiomyocyte proliferation in postnatal and adult hearts. These studies suggest that the miRNAs identified hold great promise for the treatment of cardiac pathologies consequent to cardiomyocyte loss.

A recent strategy to directly reprogram fibroblasts into cardiomyocytes using a combination of three or four cardiac-specific transcriptional factors, Gata4, Mef2c, Tbx5 and/or Hand2, in vitro [104] and in vivo $[105,106]$ is an exciting breakthrough. Reports indicate that miRNAs in synergy with cardiac transcriptional factors might regulate reprogramming process. Jayawardena et al. (2012) [107] demonstrated that miRNA-1 is sufficient to induce reprogramming of fibroblast into cardiomyocytes, however, the efficiency was significantly enhanced by adding miRNAs-133, -208 and -499 and JAK inhibitor I. Importantly, administration of these miRNAs into ischemic mouse myocardium resulted in evidence of direct conversion of cardiac fibroblasts to cardiomyocytes in situ [107].

Following myocardial infarction, successful formation of new vasculature in the injured myocardium is important to restore myocardial perfusion and therefore cardiac function. Meloni et al. (2013) [94] have shown that myocardial infarction induction in mice decreased miRNA-24 expression in the peri-infarct tissue and its resident cardiomyocytes and fibroblasts; while it is increased in endothelial cells (ECs). In vitro, miRNA-24 inhibition enhanced human ECs survival, proliferation and networking in capillary-like tubes in association with increased eNOS (a direct target of miRNA-24) [94]. In another study, endothelial cell specific miRNA-126 has been shown to impair ischemia-induced angiogenesis in a hind limb ischaemia model [108]. miRNA-126 functions in part by directly repressing negative regulators of the VEGF pathway, including the Sprouty-related protein SPRED1 and phosphoinositol-3 kinase regulatory subunit 2 (PIK3R2/p85- $\beta$ ) [109].

Recent studies have shown that miRNAs are dysregulated in early EPCs derived from patients with cardiovascular disease, which may critically limit the endogenous repair response. Early EPCs derived from patients with coronary artery disease have shown an increase in miRNAs like miRNA-21 [110], and miRNA-221/222 [111]. Moreover, over-expression of miRNA-21 in early EPCs has been shown to inhibit their migratory capacity through repression of superoxide dismutase 2 (a key protection protein against oxidative damage) and inhibition of endogenous mitogen-activated protein kinase inhibitor, sprouty-2 [110]. In another study, over-expression of miRNA-34a (mimic) inhibited EPC-mediated angiogenesis by inducing senescence via suppressing silent information regulator 1 (Sirt1) [112].

\section{Challenges of MicroRNA-Based Therapies in Cardiovascular Diseases}

Although targeting miRNAs has been used as novel therapeutic strategy, miRNA-based therapeutics faces multiple challenges. Since one miRNA might regulate a large number of targets and each gene can also be regulated by several different miRNAs, targeting of a miRNAs might potentially perturb multiple cellular functions [113]. Furthermore, this might lead to off-target effects of unidentified miRNA targets. As with any drug, the in vivo delivery of miRNA modulators and organ or tissue 
specific targeting is a challenge and therefore might require an addition of modulators such as cell surface receptor ligands and nucleic acids that can enhance target binding to the tissue or cell type of interest [114]. In addition, short half-life and/or chemical modification of these agents might alter the biological properties and might also pose toxicity issues [114]. Despite these challenges, the use of miRNAs hold great promise, since these molecules are naturally occurring endogenous regulators of cell processes that are often dysregulated in disease. These challenges could be overcome by further in-depth understanding of the miRNA biology and regulation in different disease processes and validation of target mRNAs. Also, development of more selective and stable mimics and modulators of miRNA, could lead to better approaches to target miRNAs in various diseases.

\section{Clinical Perspectives and Conclusions}

Numerous studies have shown that cardiac and circulating miRNAs are markedly altered in patients with heart failure [115-117]. miRNAs have emerged as a novel class of key regulators in various biological processes involved in cardiovascular diseases like fibrosis, hypertrophy, endothelial homeostasis, arrhythmias, stem cell-mediated repair and cardiac regeneration (summarized in Table 1 and Figure 1). As a result of tissue hypoxia, several key processes, such as inflammation; angiogenesis; cell death by apoptosis, autophagy and necrosis; fibrosis and hypertrophy are activated. miRNAs have been implicated in all of the above processes and might be released into the circulation, and therefore, serve as novel and sensitive biomarkers of cardiac damage [118]. Interestingly, these miRNAs might also be packaged within exosomes and microvesicles and circulate in a stable form in many body fluids, including blood, suggesting that they might possibly act as key molecules in cell-to-cell communications and signaling [28]. Interestingly, miRNA expression in EPCs was associated with the prognosis of chronic heart failure secondary to ischemic cardiomyopathy or non-ischemic cardiomyopathy [119]. These studies suggest that detection of circulating miRNAs could be used as diagnostic and/or prognostic markers of cardiovascular diseases. Also, considering the potential role of miRNAs in a multitude of human diseases, miRNAs and their respective targets may represent an exciting prospect for therapeutic applications to limit cardiac damage and promote tissue regeneration after myocardial infarction, stroke, or other ischemic events.

Therefore, understanding miRNA biogenesis, their interactions with regulatory signaling cascades and miRNA profiling in cardiac diseases is not only necessary for an optimized, targeted therapy, but might also provide novel opportunities to dissect their key role in cardiovascular development, homeostasis, disease pathogenesis, relevant stem cell function and regeneration.

Table 1. Potential targets of miRNA associated with cardiovascular biology.

\begin{tabular}{lll}
\hline miRNA & Targets & References \\
\hline Cardiac Development & & \\
miRNA-1-2 & Irx4, Hrt2, Hand1 and Gata6 & {$[120]$} \\
miRNA-1 & MyoD, Hand2 & {$[41,42]$} \\
miRNA-133 & Mef2 & {$[41,42]$} \\
miRNA-133a & SRF and cyclin D2 & {$[43]$} \\
miRNA-17-92 & STAT3 & {$[44,121]$} \\
miRNA-20 & Egln3 & {$[122]$} \\
\hline
\end{tabular}


Table 1. Cont.

\begin{tabular}{|c|c|c|}
\hline miRNA & Targets & References \\
\hline miRNA-23b & $\mathrm{Rb}$ phosphorylation & [123] \\
\hline miRNA-24 & BIM and GATA & [94] \\
\hline miRNA-30c & CTGF & [79] \\
\hline miRNA-143 & Adducin 3 & [124] \\
\hline \multicolumn{3}{|c|}{ Cardiac Hypertrophy } \\
\hline miRNA-150 & ACVR2A, c-myb & [125] \\
\hline miRNA-208 & THRAP1, Myostatin & [56] \\
\hline miRNA-23a & MuRF1 & [126] \\
\hline miRNA-24 & NLK & [127] \\
\hline miRNA-21 & SPRY2 & [128] \\
\hline miRNA-195 & MO25 & {$[63]$} \\
\hline miRNA-199 & Dyrk1a, Hif-1a, Sirt1 & [129-132] \\
\hline miRNA-1 & RASGAP, MEF2A, GATA4 & {$[60,133]$} \\
\hline miRNA-26b & GSK3 $\beta$ & {$[134]$} \\
\hline miRNA-27a & TGF- $\beta 1$ & [135] \\
\hline miRNA-143 & ACE2 & [136] \\
\hline miRNA-29 & TGFB3 & [127] \\
\hline miRNA-133 & Nelf-A/WHSC2, Rho & [137] \\
\hline \multicolumn{3}{|c|}{ Cardiac Fibrosis } \\
\hline miRNA-21 & Spry1, PTEN & {$[77]$} \\
\hline miRNA-133 & CTGF & [79] \\
\hline miRNA-29 & COL4A5 & {$[16]$} \\
\hline \multicolumn{3}{|c|}{ Cardiac Arrhythmia } \\
\hline miRNA-1 & KCNJ2 GJA1 & {$[75]$} \\
\hline miRNA-133 & KCNQ1 and SRF & [138] \\
\hline miRNA-133a & $\mathrm{Cx} 43$ & [82] \\
\hline miRNA-212 & Kir2.1 & {$[83,84]$} \\
\hline miRNA-17-92 & Pitx2 & [87] \\
\hline miRNA-106b & Pitx2 & {$[87]$} \\
\hline miRNA-150 & AT1R & {$[88]$} \\
\hline \multicolumn{3}{|c|}{ Cardiac Regeneration } \\
\hline miRNA-15a & Chek1 & [102] \\
\hline miRNA-17-92 & PTEN & [103] \\
\hline miRNA-195 & Chek1 & [102] \\
\hline miRNA-133 & mps1, cdc37, PA2G4, cx43, cldn5 & [139] \\
\hline miRNA-208 & $\beta \mathrm{MHC}$ & {$[41]$} \\
\hline miRNA-499 & Sox6 and Rod 1 & [115] \\
\hline miRNA-24 & eNOS & [94] \\
\hline \multicolumn{3}{|c|}{ Stem/Progenitor Cells Differentiation } \\
\hline miRNA-21 & SPRY2 & [110] \\
\hline miRNA-221 & Bim & [140] \\
\hline miRNA-34a & Sirt1 & [112] \\
\hline miRNA-126 & Spred1 & {$[109,141]$} \\
\hline
\end{tabular}


Figure 1. Role of miRNAs in cardiac development, disease and regeneration. $\uparrow$ Increasing, $\downarrow$ Decreasing,

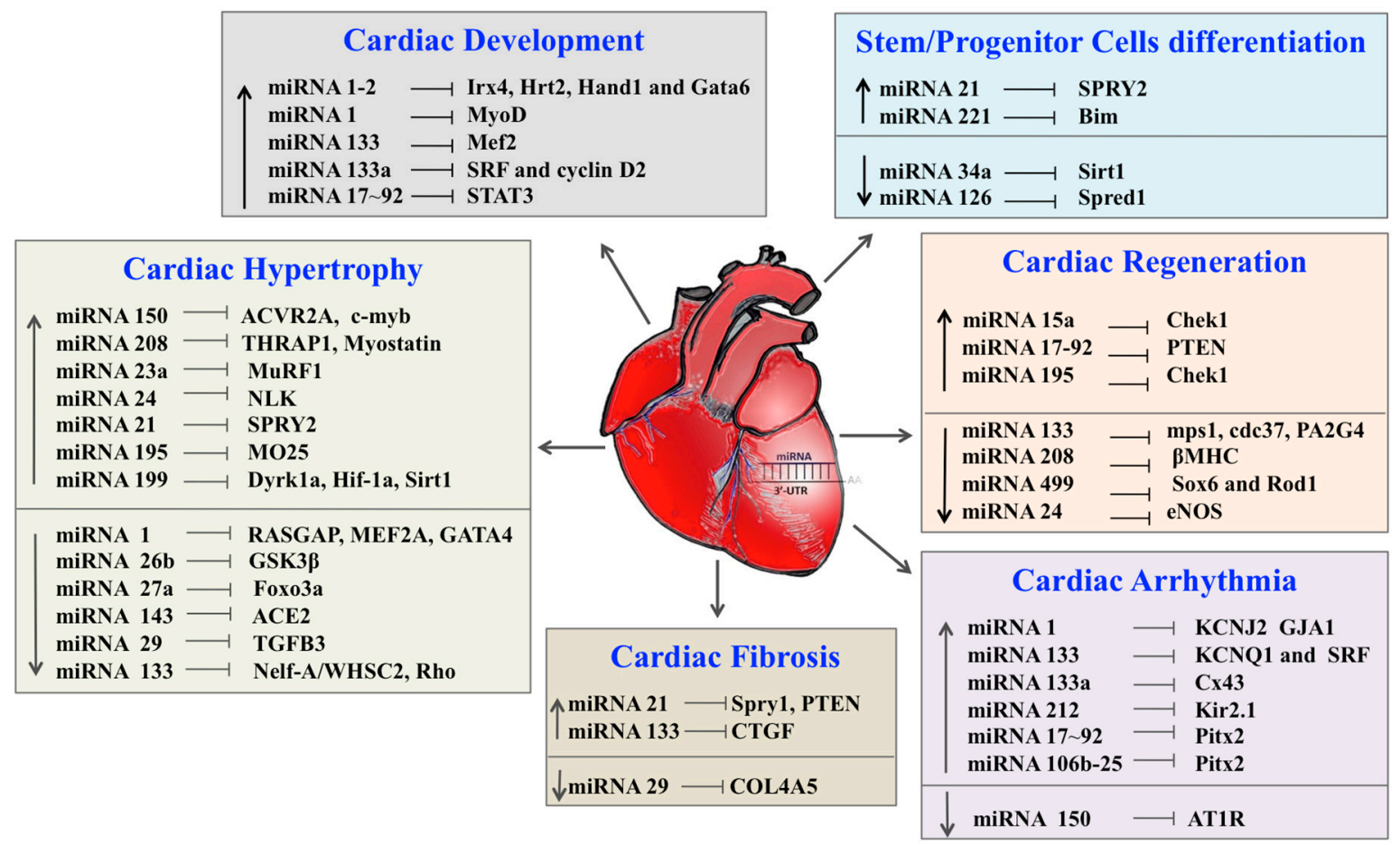

\section{Acknowledgments}

This work was supported, in part, by the National Institutes of Health (NIH) grant 1R01HL116729 (to P.K.) and American Heart Association National-The Davee Foundation SDG Grant 0530350N (to P.K.).

\section{Author Contributions}

D.J. wrote the manuscript, analysis and interpretation of the literature and revision; R.A.T. analysis and interpretation of the manuscript, contributed to drafting the manuscript and revision; S.S.B. contributed to the revision of the manuscript, intellectually and thorough interpretation of literature; P.K. significantly contributed to drafting of the manuscript, evaluation of the manuscript and critical revision.

\section{Conflicts of Interest}

The authors declare no conflict of interest.

\section{References}


1. Go, A.S.; Mozaffarian, D.; Roger, V.L.; Benjamin, E.J.; Berry, J.D.; Blaha, M.J.; Dai, S.; Ford, E.S.; Fox, C.S.; Franco, S.; et al. Heart disease and stroke statistics-2014 update: A report from the American Heart Association. Circulation 2014, 129, e28-e292.

2. Mathers, C.D.; Loncar, D. Projections of global mortality and burden of disease from 2002 to 2030. PLoS Med. 2006, 3, e442.

3. Lopez, A.D.; Mathers, C.D.; Ezzati, M.; Jamison, D.T.; Murray, C.J. Global and regional burden of disease and risk factors, 2001: Systematic analysis of population health data. Lancet 2006, 367, 1747-1757.

4. Chen, J.; Wang, D.Z. MicroRNAs in cardiovascular development. J. Mol. Cell. Cardiol. 2012, 52, 949-957.

5. Liu, N.; Olson, E.N. MicroRNA regulatory networks in cardiovascular development. Dev. Cell 2010, 18, 510-525.

6. Kishore, R.; Verma, S.K.; Mackie, A.R.; Vaughan, E.E.; Abramova, T.V.; Aiko, I.; Krishnamurthy, P. Bone marrow progenitor cell therapy-mediated paracrine regulation of cardiac miRNA-155 modulates fibrotic response in diabetic hearts. PLoS One 2013, 8, e60161.

7. Liu, D.; Fan, J.; Zeng, W.; Zhou, Y.; Ingvarsson, S.; Chen, H. Quantitative analysis of miRNA expression in several developmental stages of human livers. Hepatol. Res. 2010, 40, 813-822.

8. Abdelmohsen, K.; Srikantan, S.; Kuwano, Y. Gorospe M. miR-519 reduces cell proliferation by lowering RNA-binding protein HuR levels. Proc. Natl. Acad. Sci. USA 2008, 105, 20297-20302.

9. Bartel, D.P. MicroRNAs: Genomics, biogenesis, mechanism, and function. Cell 2004, 116, 281-297.

10. Cascio, S.; D’Andrea, A.; Ferla, R.; Surmacz, E.; Gulotta, E.; Amodeo, V.; Bazan, V.; Gebbia, N.; Russo, A. miR-20b modulates VEGF expression by targeting HIF-1 $\alpha$ and STAT3 in MCF-7 breast cancer cells. J. Cell. Physiol. 2010, 224, 242-249.

11. El Ouaamari, A.; Baroukh, N.; Martens, G.A.; Lebrun, P.; Pipeleers, D.; van Obberghen, E. miR-375 targets 3'-phosphoinositide-dependent protein kinase-1 and regulates glucose-induced biological responses in pancreatic $\beta$-cells. Diabetes 2008, 57, 2708-2717.

12. Esau, C.; Davis, S.; Murray, S.F.; Yu, X.X.; Pandey, S.K.; Pear, M.; Watts, L.; Booten, S.L.; Graham, M.; McKay, R.; et al. miR-122 regulation of lipid metabolism revealed by in vivo antisense targeting. Cell Metab. 2006, 3, 87-98.

13. Fish, J.E.; Srivastava, D. MicroRNAs: Opening a new vein in angiogenesis research. Sci. Signal. 2009, 2, pe1.

14. Ivey, K.N.; Muth, A.; Arnold, J.; King, F.W.; Yeh, R.F.; Fish, J.E.; Hsiao, E.C.; Schwartz, R.J.; Conklin, B.R.; Bernstein, H.S.; et al. MicroRNA regulation of cell lineages in mouse and human embryonic stem cells. Cell Stem Cell 2008, 2, 219-229.

15. Urbich, C.; Kuehbacher, A.; Dimmeler, S. Role of microRNAs in vascular diseases, inflammation, and angiogenesis. Cardiovasc. Res. 2008, 79, 581-588.

16. Van Rooij, E.; Sutherland, L.B.; Thatcher, J.E.; DiMaio, J.M.; Naseem, R.H.; Marshall, W.S.; Hill, J.A.; Olson, E.N. Dysregulation of microRNAs after myocardial infarction reveals a role of miR-29 in cardiac fibrosis. Proc. Natl. Acad. Sci. USA 2008, 105, 13027-13032.

17. Lee, R.C.; Feinbaum, R.L.; Ambros, V. The C. elegans heterochronic gene lin-4 encodes small RNAs with antisense complementarity to lin-14. Cell 1993, 75, 843-854. 
18. Wightman, B.; Ha, I.; Ruvkun, G. Posttranscriptional regulation of the heterochronic gene lin-14 by lin-4 mediates temporal pattern formation in C. elegans. Cell 1993, 75, 855-862.

19. Lewis, B.P.; Burge, C.B.; Bartel, D.P. Conserved seed pairing, often flanked by adenosines, indicates that thousands of human genes are microRNA targets. Cell 2005, 120, 15-20.

20. Friedman, R.C.; Farh, K.K.; Burge, C.B.; Bartel, D.P. Most mammalian mRNAs are conserved targets of microRNAs. Genome Res. 2009, 19, 92-105.

21. Lee, Y.; Kim, M.; Han, J.; Yeom, K.H.; Lee, S.; Baek, S.H.; Kim, V.N. MicroRNA genes are transcribed by RNA polymerase II. EMBO J. 2004, 23, 4051-4060.

22. Ha, M.; Kim, V.N. Regulation of microRNA biogenesis. Nat. Rev. Mol. Cell Biol. 2014, 15, 509-524.

23. Bartel, D.P. MicroRNAs: Target recognition and regulatory functions. Cell 2009, 136, 215-233.

24. Kim, V.N.; Han, J.; Siomi, M.C. Biogenesis of small RNAs in animals. Nat. Rev. Mol. Cell Biol. 2009, 10, 126-139.

25. Guo, H.; Ingolia, N.T.; Weissman, J.S.; Bartel, D.P. Mammalian microRNAs predominantly act to decrease target mRNA levels. Nature 2010, 466, 835-840.

26. Vasudevan, S.; Tong, Y.; Steitz, J.A. Switching from repression to activation: MicroRNAs can up-regulate translation. Science 2007, 318, 1931-1934.

27. Chi, S.W.; Zang, J.B.; Mele, A.; Darnell, R.B. Argonaute HITS-CLIP decodes microRNA-mRNA interaction maps. Nature 2009, 460, 479-486.

28. Corrado, C.; Raimondo, S.; Chiesi, A.; Ciccia, F.; de Leo, G.; Alessandro, R. Exosomes as intercellular signaling organelles involved in health and disease: Basic science and clinical applications. Int. J. Mol. Sci. 2013, 14, 5338-5366.

29. Vo, N.K.; Dalton, R.P.; Liu, N.; Olson, E.N.; Goodman, R.H. Affinity purification of microRNA-133a with the cardiac transcription factor, Hand2. Proc. Natl. Acad. Sci. USA 2010, 107, 19231-19236.

30. Hendrickson, D.G.; Hogan, D.J.; McCullough, H.L.; Myers, J.W.; Herschlag, D.; Ferrell, J.E.; Brown, P.O. Concordant regulation of translation and mRNA abundance for hundreds of targets of a human microRNA. PLoS Biol. 2009, 7, e1000238.

31. Zhao, Y.; Ransom, J.F.; Li, A.; Vedantham, V.; von Drehle, M.; Muth, A.N.; Tsuchihashi, T.; McManus, M.T.; Schwartz, R.J.; Srivastava, D. Dysregulation of cardiogenesis, cardiac conduction, and cell cycle in mice lacking miRNA-1-2. Cell 2007, 129, 303-317.

32. Rao, P.K.; Toyama, Y.; Chiang, H.R.; Gupta, S.; Bauer, M.; Medvid, R.; Reinhardt, F.; Liao, R.; Krieger, M.; Jaenisch, R.; et al. Loss of cardiac microRNA-mediated regulation leads to dilated cardiomyopathy and heart failure. Circ. Res. 2009, 105, 585-594.

33. Olson, E.N.; Schneider, M.D. Sizing up the heart: Development redux in disease. Genes Dev. 2003, 17, 1937-1956.

34. Li, F.; Wang, X.; Capasso, J.M.; Gerdes, A.M. Rapid transition of cardiac myocytes from hyperplasia to hypertrophy during postnatal development. J. Mol. Cell. Cardiol. 1996, 28, 1737-1746.

35. Kajstura, J.; Zhang, X.; Reiss, K.; Szoke, E.; Li, P.; Lagrasta, C.; Cheng, W.; Darzynkiewicz, Z.; Olivetti, G.; Anversa, P. Myocyte cellular hyperplasia and myocyte cellular hypertrophy contribute 
to chronic ventricular remodeling in coronary artery narrowing-induced cardiomyopathy in rats. Circ. Res. 1994, 74, 383-400.

36. Paradis, A.; Xiao, D.; Zhou, J.; Zhang, L. Endothelin-1 promotes cardiomyocyte terminal differentiation in the developing heart via heightened DNA methylation. Int. J. Med. Sci. 2014, 11, 373-380.

37. Schupp, M.O.; Waas, M.; Chun, C.Z.; Ramchandran, R. Transcriptional inhibition of etv2 expression is essential for embryonic cardiac development. Dev. Biol. 2014, 393, 71-83.

38. Deb, A.; Ubil, E. Cardiac fibroblast in development and wound healing. J. Mol. Cell. Cardiol. 2014, 70, 47-55.

39. Ieda, M. Heart development and regeneration via cellular interaction and reprogramming. Keio J. Med. 2013, 62, 99-106.

40. Peralta, M.; Gonzalez-Rosa, J.M.; Marques, I.J.; Mercader, N. The epicardium in the embryonic and adult zebrafish. J. Dev. Biol. 2014, 2, 101-116.

41. Liu, N.; Williams, A.H.; Kim, Y.; McAnally, J.; Bezprozvannaya, S.; Sutherland, L.B.; Richardson, J.A.; Bassel-Duby, R.; Olson, E.N. An intragenic MEF2-dependent enhancer directs muscle-specific expression of microRNAs 1 and 133. Proc. Natl. Acad. Sci. USA 2007, 104, 20844-20849.

42. Zhao, Y.; Samal, E.; Srivastava, D. Serum response factor regulates a muscle-specific microRNA that targets Hand2 during cardiogenesis. Nature 2005, 436, 214-220.

43. Liu, N.; Bezprozvannaya, S.; Williams, A.H.; Qi, X.; Richardson, J.A.; Bassel-Duby, R.; Olson, E.N. microRNA-133a regulates cardiomyocyte proliferation and suppresses smooth muscle gene expression in the heart. Genes Dev. 2008, 22, 3242-3254.

44. Ventura, A.; Young, A.G.; Winslow, M.M.; Lintault, L.; Meissner, A.; Erkeland, S.J.; Newman, J.; Bronson, R.T.; Crowley, D.; Stone, J.R.; et al. Targeted deletion reveals essential and overlapping functions of the miR-17 through 92 family of miRNA clusters. Cell 2008, 132, $875-886$.

45. Thum, T.; Galuppo, P.; Wolf, C.; Fiedler, J.; Kneitz, S.; van Laake, L.W.; Doevendans, P.A.; Mummery, C.L.; Borlak, J.; Haverich, A.; et al. MicroRNAs in the human heart: A clue to fetal gene reprogramming in heart failure. Circulation 2007, 116, 258-267.

46. Watanabe, K.; Thandavarayan, R.A.; Harima, M.; Sari, F.R.; Gurusamy, N.; Veeraveedu, P.T.; Mito, S.; Arozal, W.; Sukumaran, V.; Laksmanan, A.P.; et al. Role of differential signaling pathways and oxidative stress in diabetic cardiomyopathy. Curr. Cardiol. Rev. 2010, 6, 280-290.

47. Watanabe, K.; Thandavarayan, R.A.; Gurusamy, N.; Zhang, S.; Muslin, A.J.; Suzuki, K.; Tachikawa, H.; Kodama, M.; Aizawa, Y. Role of 14-3-3 protein and oxidative stress in diabetic cardiomyopathy. Acta Physiol. Hung. 2009, 96, 277-287.

48. Thandavarayan, R.A.; Watanabe, K.; Ma, M.; Gurusamy, N.; Veeraveedu, P.T.; Konishi, T.; Zhang, S.; Muslin, A.J.; Kodama, M.; Aizawa, Y. Dominant-negative p38a mitogen-activated protein kinase prevents cardiac apoptosis and remodeling after streptozotocin-induced diabetes mellitus. Am. J. Physiol. Heart Circ. Physiol. 2009, 297, H911-H919.

49. Thandavarayan, R.A.; Giridharan, V.V.; Sari, F.R.; Arumugam, S.; Veeraveedu, P.T.; Pandian, G.N.; Palaniyandi, S.S.; Ma, M.; Suzuki, K.; Gurusamy, N.; et al. Depletion of 14-3-3 protein exacerbates cardiac oxidative stress, inflammation and remodeling process via 
modulation of MAPK/NF- $\kappa \mathrm{B}$ signaling pathways after streptozotocin-induced diabetes mellitus. Cell. Physiol. Biochem. 2011, 28, 911-922.

50. McCarthy, J.J.; Esser, K.A. MicroRNA-1 and microRNA-133a expression are decreased during skeletal muscle hypertrophy. J. Appl. Physiol. 2007, 102, 306-313.

51. Krishnamurthy, P.; Subramanian, V.; Singh, M.; Singh, K. $\beta 1$ integrins modulate $\beta$-adrenergic receptor-stimulated cardiac myocyte apoptosis and myocardial remodeling. Hypertension 2007, 49, 865-872.

52. Verma, S.K.; Krishnamurthy, P.; Barefield, D.; Singh, N.; Gupta, R.; Lambers, E.; Thal, M.; Mackie, A.; Hoxha, E.; Ramirez, V.; et al. Interleukin-10 treatment attenuates pressure overload-induced hypertrophic remodeling and improves heart function via signal transducers and activators of transcription 3-dependent inhibition of nuclear factor- $\kappa \mathrm{B}$. Circulation 2012 , 126, 418-429.

53. Rajabi, M.; Kassiotis, C.; Razeghi, P.; Taegtmeyer, H. Return to the fetal gene program protects the stressed heart: A strong hypothesis. Heart Fail. Rev. 2007, 12, 331-343.

54. Mooren, F.C.; Viereck, J.; Kruger, K.; Thum, T. Circulating microRNAs as potential biomarkers of aerobic exercise capacity. Am. J. Physiol. Heart Circ. Physiol. 2014, 306, H557-H563.

55. Martinelli, N.C.; Cohen, C.R.; Santos, K.G.; Castro, M.A.; Biolo, A.; Frick, L.; Silvello, D.; Lopes, A.; Schneider, S.; Andrades, M.E.; et al. An analysis of the global expression of microRNAs in an experimental model of physiological left ventricular hypertrophy. PLoS One 2014, 9, e93271.

56. Callis, T.E.; Pandya, K.; Seok, H.Y.; Tang, R.H.; Tatsuguchi, M.; Huang, Z.P.; Chen, J.F.; Deng, Z.; Gunn, B.; Shumate, J.; et al. MicroRNA-208a is a regulator of cardiac hypertrophy and conduction in mice. J. Clin. Investig. 2009, 119, 2772-2786.

57. Van Rooij, E.; Sutherland, L.B.; Liu, N.; Williams, A.H.; McAnally, J.; Gerard, R.D.; Richardson, J.A.; Olson, E.N. A signature pattern of stress-responsive microRNAs that can evoke cardiac hypertrophy and heart failure. Proc. Natl. Acad. Sci. USA 2006, 103, 18255-18260.

58. Chen, J.F.; Murchison, E.P.; Tang, R.; Callis, T.E.; Tatsuguchi, M.; Deng, Z.; Rojas, M.; Hammond, S.M.; Schneider, M.D.; Selzman, C.H.; et al. Targeted deletion of Dicer in the heart leads to dilated cardiomyopathy and heart failure. Proc. Natl. Acad. Sci. USA 2008, 105, 2111-2116.

59. Cheng, Y.; Ji, R.; Yue, J.; Yang, J.; Liu, X.; Chen, H.; Dean, D.B.; Zhang, C. MicroRNAs are aberrantly expressed in hypertrophic heart: Do they play a role in cardiac hypertrophy? Am. J. Pathol. 2007, 170, 1831-1840.

60. Sayed, D.; Hong, C.; Chen, I.Y.; Lypowy, J.; Abdellatif, M. MicroRNAs play an essential role in the development of cardiac hypertrophy. Circ. Res. 2007, 100, 416-424.

61. Ikeda, S.; Kong, S.W.; Lu, J.; Bisping, E.; Zhang, H.; Allen, P.D.; Golub, T.R.; Pieske, B.; $\mathrm{Pu}$, W.T. Altered microRNA expression in human heart disease. Physiol. Genomics 2007, 31, 367-373.

62. Tatsuguchi, M.; Seok, H.Y.; Callis, T.E.; Thomson, J.M.; Chen, J.F.; Newman, M.; Rojas, M.; Hammond, S.M.; Wang, D.Z. Expression of microRNAs is dynamically regulated during cardiomyocyte hypertrophy. J. Mol. Cell. Cardiol. 2007, 42, 1137-1141. 
63. Chen, H.; Untiveros, G.M.; McKee, L.A.; Perez, J.; Li, J.; Antin, P.B.; Konhilas, J.P. Micro-RNA-195 and -451 regulate the LKB1/AMPK signaling axis by targeting MO25. PLoS One 2012, 7, e41574.

64. Montgomery, R.L.; Hullinger, T.G.; Semus, H.M.; Dickinson, B.A.; Seto, A.G.; Lynch, J.M.; Stack, C.; Latimer, P.A.; Olson, E.N.; van Rooij, E. Therapeutic inhibition of miR-208a improves cardiac function and survival during heart failure. Circulation 2011, 124, 1537-1547.

65. Bang, C.; Batkai, S.; Dangwal, S.; Gupta, S.K.; Foinquinos, A.; Holzmann, A.; Just, A.; Remke, J.; Zimmer, K.; Zeug, A.; et al. Cardiac fibroblast-derived microRNA passenger strand-enriched exosomes mediate cardiomyocyte hypertrophy. J. Clin. Investig. 2014, 124, 2136-2146.

66. Rossi, M.A. Pathologic fibrosis and connective tissue matrix in left ventricular hypertrophy due to chronic arterial hypertension in humans. J. Hypertens. 1998, 16, 1031-1041.

67. Swynghedauw, B. Molecular mechanisms of myocardial remodeling. Physiol. Rev. 1999, 79, 215-262.

68. Manabe, I.; Shindo, T.; Nagai, R. Gene expression in fibroblasts and fibrosis: Involvement in cardiac hypertrophy. Circ. Res. 2002, 91, 1103-1113.

69. Brown, R.D.; Ambler, S.K.; Mitchell, M.D.; Long, C.S. The cardiac fibroblast: Therapeutic target in myocardial remodeling and failure. Annu. Rev. Pharmacol. Toxicol. 2005, 45, 657-687.

70. Khan, R.; Sheppard, R. Fibrosis in heart disease: Understanding the role of transforming growth factor- $\beta$ in cardiomyopathy, valvular disease and arrhythmia. Immunology 2006, 118, 10-24.

71. Martos, R.; Baugh, J.; Ledwidge, M.; O’Loughlin, C.; Conlon, C.; Patle, A.; Donnelly, S.C.; McDonald, K. Diastolic heart failure: Evidence of increased myocardial collagen turnover linked to diastolic dysfunction. Circulation 2007, 115, 888-895.

72. Benjamin, I.J.; Jalil, J.E.; Tan, L.B.; Cho, K.; Weber, K.T.; Clark, W.A. Isoproterenol-induced myocardial fibrosis in relation to myocyte necrosis. Circ. Res. 1989, 65, 657-670.

73. Buja, L.M.; Willerson, J.T. The role of coronary artery lesions in ischemic heart disease: Insights from recent clinicopathologic, coronary arteriographic, and experimental studies. Hum. Pathol. 1987, 18, 451-461.

74. Krishnamurthy, P.; Peterson, J.T.; Subramanian, V.; Singh, M.; Singh, K. Inhibition of matrix metalloproteinases improves left ventricular function in mice lacking osteopontin after myocardial infarction. Mol. Cell. Biochem. 2009, 322, 53-62.

75. Yang, B.; Lin, H.; Xiao, J.; Lu, Y.; Luo, X.; Li, B.; Zhang, Y.; Xu, C.; Bai, Y.; Wang, H.; et al. The muscle-specific microRNA miR-1 regulates cardiac arrhythmogenic potential by targeting GJA1 and KCNJ2. Nat. Med. 2007, 13, 486-491.

76. Ichimura, A.; Ruike, Y.; Terasawa, K.; Tsujimoto, G. miRNAs and regulation of cell signaling. FEBS J. 2011, 278, 1610-1618.

77. Thum, T.; Gross, C.; Fiedler, J.; Fischer, T.; Kissler, S.; Bussen, M.; Galuppo, P.; Just, S.; Rottbauer, W.; Frantz, S.; et al. MicroRNA-21 contributes to myocardial disease by stimulating MAP kinase signalling in fibroblasts. Nature 2008, 456, 980-984.

78. Roy, S.; Khanna, S.; Hussain, S.R.; Biswas, S.; Azad, A.; Rink, C.; Gnyawali, S.; Shilo, S.; Nuovo, G.J.; Sen, C.K. MicroRNA expression in response to murine myocardial infarction: miR-21 regulates fibroblast metalloprotease-2 via phosphatase and tensin homologue. Cardiovasc. Res. 2009, 82, 21-29. 
79. Duisters, R.F.; Tijsen, A.J.; Schroen, B.; Leenders, J.J.; Lentink, V.; van der Made, I.; Herias, V.; van Leeuwen, R.E.; Schellings, M.W.; Barenbrug, P.; et al. miR-133 and miR-30 regulate connective tissue growth factor: Implications for a role of microRNAs in myocardial matrix remodeling. Circ. Res. 2009, 104, 170-178.

80. He, B.; Xiao, J.; Ren, A.J.; Zhang, Y.F.; Zhang, H.; Chen, M.; Xie, B.; Gao, X.G.; Wang, Y.W. Role of miR-1 and miR-133a in myocardial ischemic postconditioning. J. Biomed. Sci. 2011, $18,22$.

81. Danowski, N.; Manthey, I.; Jakob, H.G.; Siffert, W.; Peters, J.; Frey, U.H. Decreased expression of miR-133a but not of miR-1 is associated with signs of heart failure in patients undergoing coronary bypass surgery. Cardiology 2013, 125, 125-130.

82. Osbourne, A.; Calway, T.; Broman, M.; McSharry, S.; Earley, J.; Kim, G.H. Downregulation of connexin43 by microRNA-130a in cardiomyocytes results in cardiac arrhythmias. J. Mol. Cell. Cardiol. 2014, 74, 53-63.

83. Ucar, A.; Gupta, S.K.; Fiedler, J.; Erikci, E.; Kardasinski, M.; Batkai, S.; Dangwal, S.; Kumarswamy, R.; Bang, C.; Holzmann, A.; et al. The miRNA-212/132 family regulates both cardiac hypertrophy and cardiomyocyte autophagy. Nat. Commun. 2012, 3, 1078.

84. Xiao, J.; Liang, D.; Zhang, Y.; Liu, Y.; Zhang, H.; Liu, Y.; Li, L.; Liang, X.; Sun, Y.; Chen, Y.H. MicroRNA expression signature in atrial fibrillation with mitral stenosis. Physiol. Genomics 2011, 43, 655-664.

85. Chinchilla, A.; Daimi, H.; Lozano-Velasco, E.; Dominguez, J.N.; Caballero, R.; Delpon, E.; Tamargo, J.; Cinca, J.; Hove-Madsen, L.; Aranega, A.E.; et al. PITX2 insufficiency leads to atrial electrical and structural remodeling linked to arrhythmogenesis. Circ. Cardiovasc. Genet. 2011, 4, 269-279.

86. Wang, J.; Klysik, E.; Sood, S.; Johnson, R.L.; Wehrens, X.H.; Martin, J.F. Pitx2 prevents susceptibility to atrial arrhythmias by inhibiting left-sided pacemaker specification. Proc. Natl. Acad. Sci. USA 2010, 107, 9753-9758.

87. Wang, J.; Bai, Y.; Li, N.; Ye, W.; Zhang, M.; Greene, S.B.; Tao, Y.; Chen, Y.; Wehrens, X.H.; Martin, J.F. Pitx2-microRNA pathway that delimits sinoatrial node development and inhibits predisposition to atrial fibrillation. Proc. Natl. Acad. Sci. USA 2014, 111, 9181-9186.

88. Goren, Y.; Meiri, E.; Hogan, C.; Mitchell, H.; Lebanony, D.; Salman, N.; Schliamser, J.E.; Amir, O. Relation of reduced expression of miR-150 in platelets to atrial fibrillation in patients with chronic systolic heart failure. Am. J. Cardiol. 2014, 113, 976-981.

89. Xiao, J.; Luo, X.; Lin, H.; Zhang, Y.; Lu, Y.; Wang, N.; Zhang, Y.; Yang, B.; Wang, Z. MicroRNA miR-133 represses HERG $\mathrm{K}^{+}$channel expression contributing to QT prolongation in diabetic hearts. J. Biol. Chem. 2007, 282, 12363-12367.

90. Bauters, C.; Lamblin, N.; Mc Fadden, E.P.; van Belle, E.; Millaire, A.; de Groote, P. Influence of diabetes mellitus on heart failure risk and outcome. Cardiovasc. Diabetol. 2003, 2, 1.

91. Li, Y.; Yang, C.M.; Xi, Y.; Wu, G.; Shelat, H.; Gao, S.; Cheng, J.; Geng, Y.J. MicroRNA-1/133 targeted dysfunction of potassium channels KCNE1 and KCNQ1 in human cardiac progenitor cells with simulated hyperglycemia. Int. J. Cardiol. 2013, 167, 1076-1078. 
92. Fasanaro, P.; D’Alessandra, Y.; di Stefano, V.; Melchionna, R.; Romani, S.; Pompilio, G.; Capogrossi, M.C.; Martelli, F. MicroRNA-210 modulates endothelial cell response to hypoxia and inhibits the receptor tyrosine kinase ligand Ephrin-A3. J. Biol. Chem. 2008, 283, 15878-15883.

93. Icli, B.; Wara, A.K.; Moslehi, J.; Sun, X.; Plovie, E.; Cahill, M.; Marchini, J.F.; Schissler, A.; Padera, R.F.; Shi, J.; et al. MicroRNA-26a regulates pathological and physiological angiogenesis by targeting BMP/SMAD1 signaling. Circ. Res. 2013, 113, 1231-1241.

94. Meloni, M.; Marchetti, M.; Garner, K.; Littlejohns, B.; Sala-Newby, G.; Xenophontos, N.; Floris, I.; Suleiman, M.S.; Madeddu, P.; Caporali, A.; et al. Local inhibition of microRNA-24 improves reparative angiogenesis and left ventricle remodeling and function in mice with myocardial infarction. Mol. Ther. 2013, 21, 1390-1402.

95. Dentelli, P.; Rosso, A.; Orso, F.; Olgasi, C.; Taverna, D.; Brizzi, M.F. microRNA-222 controls neovascularization by regulating signal transducer and activator of transcription 5A expression. Arterioscler. Thromb. Vasc. Biol. 2010, 30, 1562-1568.

96. Liu, X.; Cheng, Y.; Zhang, S.; Lin, Y.; Yang, J.; Zhang, C. A necessary role of miR-221 and miR-222 in vascular smooth muscle cell proliferation and neointimal hyperplasia. Circ. Res. 2009, 104, 476-487.

97. Chen, Y.; Gorski, D.H. Regulation of angiogenesis through a microRNA (miR-130a) that down-regulates antiangiogenic homeobox genes GAX and HOXA5. Blood 2008, 111, 1217-1226.

98. Sessa, R.; Seano, G.; di Blasio, L.; Gagliardi, P.A.; Isella, C.; Medico, E.; Cotelli, F.; Bussolino, F.; Primo, L. The miR-126 regulates angiopoietin-1 signaling and vessel maturation by targeting p85ß. Biochim. Biophys. Acta 2012, 1823, 1925-1935.

99. Porrello, E.R.; Mahmoud, A.I.; Simpson, E.; Hill, J.A.; Richardson, J.A.; Olson, E.N.; Sadek, H.A. Transient regenerative potential of the neonatal mouse heart. Science 2011, 331, 1078-1080.

100. Bergmann, O.; Bhardwaj, R.D.; Bernard, S.; Zdunek, S.; Barnabe-Heider, F.; Walsh, S.; Zupicich, J.; Alkass, K.; Buchholz, B.A.; Druid, H.; et al. Evidence for cardiomyocyte renewal in humans. Science 2009, 324, 98-102.

101. Mollova, M.; Bersell, K.; Walsh, S.; Savla, J.; Das, L.T.; Park, S.Y.; Silberstein, L.E.; Dos Remedios, C.G.; Graham, D.; Colan, S.; et al. Cardiomyocyte proliferation contributes to heart growth in young humans. Proc. Natl. Acad. Sci. USA 2013, 110, 1446-1451.

102. Porrello, E.R.; Johnson, B.A.; Aurora, A.B.; Simpson, E.; Nam, Y.J.; Matkovich, S.J.; Dorn, G.W., II; van Rooij, E.; Olson, E.N. MiR-15 family regulates postnatal mitotic arrest of cardiomyocytes. Circ. Res. 2011, 109, 670-679.

103. Chen, J.; Huang, Z.P.; Seok, H.Y.; Ding, J.; Kataoka, M.; Zhang, Z.; Hu, X.; Wang, G.; Lin, Z.; Wang, S.; et al. miR-17-92 cluster is required for and sufficient to induce cardiomyocyte proliferation in postnatal and adult hearts. Circ. Res. 2013, 112, 1557-1566.

104. Ieda, M.; Fu, J.D.; Delgado-Olguin, P.; Vedantham, V.; Hayashi, Y.; Bruneau, B.G.; Srivastava, D. Direct reprogramming of fibroblasts into functional cardiomyocytes by defined factors. Cell 2010, 142, 375-386. 
105. Qian, L.; Huang, Y.; Spencer, C.I.; Foley, A.; Vedantham, V.; Liu, L.; Conway, S.J.; Fu, J.D.; Srivastava, D. In vivo reprogramming of murine cardiac fibroblasts into induced cardiomyocytes. Nature 2012, 485, 593-598.

106. Song, K.; Nam, Y.J.; Luo, X.; Qi, X.; Tan, W.; Huang, G.N.; Acharya, A.; Smith, C.L.; Tallquist, M.D.; Neilson, E.G.; et al. Heart repair by reprogramming non-myocytes with cardiac transcription factors. Nature 2012, 485, 599-604.

107. Jayawardena, T.M.; Egemnazarov, B.; Finch, E.A.; Zhang, L.; Payne, J.A.; Pandya, K.; Zhang, Z.; Rosenberg, P.; Mirotsou, M.; Dzau, V.J. MicroRNA-mediated in vitro and in vivo direct reprogramming of cardiac fibroblasts to cardiomyocytes. Circ. Res. 2012, 110, 1465-1473.

108. Van Solingen, C.; Seghers, L.; Bijkerk, R.; Duijs, J.M.; Roeten, M.K.; van Oeveren-Rietdijk, A.M.; Baelde, H.J.; Monge, M.; Vos, J.B.; de Boer, H.C.; et al. Antagomir-mediated silencing of endothelial cell specific microRNA-126 impairs ischemia-induced angiogenesis. J. Cell. Mol. Med. 2009, 13, 1577-1585.

109. Fish, J.E.; Santoro, M.M.; Morton, S.U.; Yu, S.; Yeh, R.F.; Wythe, J.D.; Ivey, K.N.; Bruneau, B.G.; Stainier, D.Y.; Srivastava, D. miR-126 regulates angiogenic signaling and vascular integrity. Dev. Cell 2008, 15, 272-284.

110. Fleissner, F.; Jazbutyte, V.; Fiedler, J.; Gupta, S.K.; Yin, X.; Xu, Q.; Galuppo, P.; Kneitz, S.; Mayr, M.; Ertl, G.; et al. Short communication: Asymmetric dimethylarginine impairs angiogenic progenitor cell function in patients with coronary artery disease through a microRNA-21-dependent mechanism. Circ. Res. 2010, 107, 138-143.

111. Minami, Y.; Satoh, M.; Maesawa, C.; Takahashi, Y.; Tabuchi, T.; Itoh, T.; Nakamura, M. Effect of atorvastatin on microRNA 221/222 expression in endothelial progenitor cells obtained from patients with coronary artery disease. Eur. J. Clin. Investig. 2009, 39, 359-367.

112. Zhao, T.; Li, J.; Chen, A.F. MicroRNA-34a induces endothelial progenitor cell senescence and impedes its angiogenesis via suppressing silent information regulator 1. Am. J. Physiol. Endocrinol. Metab. 2010, 299, E110-E116.

113. Miranda, K.C.; Huynh, T.; Tay, Y.; Ang, Y.S.; Tam, W.L.; Thomson, A.M.; Lim, B.; Rigoutsos, I. A pattern-based method for the identification of microRNA binding sites and their corresponding heteroduplexes. Cell 2006, 126, 1203-1217.

114. Van Rooij, E.; Marshall, W.S.; Olson, E.N. Toward microRNA-based therapeutics for heart disease: The sense in antisense. Circ. Res. 2008, 103, 919-928.

115. Corsten, M.F.; Dennert, R.; Jochems, S.; Kuznetsova, T.; Devaux, Y.; Hofstra, L.; Wagner, D.R.; Staessen, J.A.; Heymans, S.; Schroen, B. Circulating microRNA-208b and microRNA-499 reflect myocardial damage in cardiovascular disease. Circ. Cardiovasc. Genet. 2010, 3, 499-506.

116. D’Alessandra, Y.; Devanna, P.; Limana, F.; Straino, S.; di Carlo, A.; Brambilla, P.G.; Rubino, M.; Carena, M.C.; Spazzafumo, L.; de Simone, M.; et al. Circulating microRNAs are new and sensitive biomarkers of myocardial infarction. Eur. Heart J. 2010, 31, 2765-2773.

117. Fukushima, Y.; Nakanishi, M.; Nonogi, H.; Goto, Y.; Iwai, N. Assessment of plasma miRNAs in congestive heart failure. Circ. J. 2011, 75, 336-340.

118. Van Empel, V.P.; de Windt, L.J.; da Costa Martins, P.A. Circulating miRNAs: Reflecting or affecting cardiovascular disease? Curr. Hypertens. Rep. 2012, 14, 498-509. 
119. Qiang, L.; Hong, L.; Ningfu, W.; Huaihong, C.; Jing, W. Expression of miR-126 and miR-508-5p in endothelial progenitor cells is associated with the prognosis of chronic heart failure patients. Int. J. Cardiol. 2013, 168, 2082-2088.

120. Zhao, Y.; Wang, W.; Han, L.; Rayburn, E.R.; Hill, D.L.; Wang, H.; Zhang, R. Isolation, structural determination, and evaluation of the biological activity of 20(S)-25-methoxyl-dammarane-3 $\beta, 12 \beta, 20$-triol [20(S)-25-OCH $3-P P D]$, a novel natural product from Panax notoginseng. Med. Chem. 2007, 3, 51-60.

121. Foshay, K.M.; Gallicano, G.I. miR-17 family miRNAs are expressed during early mammalian development and regulate stem cell differentiation. Dev. Biol. 2009, 326, 431-443.

122. Frank, D.; Gantenberg, J.; Boomgaarden, I.; Kuhn, C.; Will, R.; Jarr, K.U.; Eden, M.; Kramer, K.; Luedde, M.; Mairbaurl, H.; et al. MicroRNA-20a inhibits stress-induced cardiomyocyte apoptosis involving its novel target Egln3/PHD3. J. Mol. Cell. Cardiol. 2012, 52, 711-717.

123. Wang, K.C.; Garmire, L.X.; Young, A.; Nguyen, P.; Trinh, A.; Subramaniam, S.; Wang, N.; Shyy, J.Y.; Li, Y.S.; Chien, S. Role of microRNA-23b in flow-regulation of Rb phosphorylation and endothelial cell growth. Proc. Natl. Acad. Sci. USA 2010, 107, 3234-3239.

124. Deacon, D.C.; Nevis, K.R.; Cashman, T.J.; Zhou, Y.; Zhao, L.; Washko, D.; Guner-Ataman, B.; Burns, C.G.; Burns, C.E. The miR-143-adducin3 pathway is essential for cardiac chamber morphogenesis. Development 2010, 137, 1887-1896.

125. Li, X.; Kong, M.; Jiang, D.; Qian, J.; Duan, Q.; Dong, A. MicroRNA-150 aggravates $\mathrm{H}_{2} \mathrm{O}_{2}$-induced cardiac myocyte injury by down-regulating c-myb gene. Acta Biochim. Biophys. Sin. 2013, 45, 734-741.

126. Lin, Z.; Murtaza, I.; Wang, K.; Jiao, J.; Gao, J.; Li, P.F. miR-23a functions downstream of NFATc3 to regulate cardiac hypertrophy. Proc. Natl. Acad. Sci. USA 2009, 106, 12103-12108.

127. Diao, X.; Shen, E.; Wang, X.; Hu, B. Differentially expressed microRNAs and their target genes in the hearts of streptozotocin-induced diabetic mice. Mol. Med. Rep. 2011, 4, 633-640.

128. Sayed, D.; Rane, S.; Lypowy, J.; He, M.; Chen, I.Y.; Vashistha, H.; Yan, L.; Malhotra, A.; Vatner, D.; Abdellatif, M. MicroRNA-21 targets Sprouty2 and promotes cellular outgrowths. Mol. Biol. Cell 2008, 19, 3272-3282.

129. Van Rooij, E.; Doevendans, P.A.; de Theije, C.C.; Babiker, F.A.; Molkentin, J.D.; de Windt, L.J. Requirement of nuclear factor of activated T-cells in calcineurin-mediated cardiomyocyte hypertrophy. J. Biol. Chem. 2002, 277, 48617-48626.

130. Arron, J.R.; Winslow, M.M.; Polleri, A.; Chang, C.P.; Wu, H.; Gao, X.; Neilson, J.R.; Chen, L.; Heit, J.J.; Kim, S.K.; et al. NFAT dysregulation by increased dosage of DSCR1 and DYRK1A on chromosome 21. Nature 2006, 441, 595-600.

131. Song, X.W.; Li, Q.; Lin, L.; Wang, X.C.; Li, D.F.; Wang, G.K.; Ren, A.J.; Wang, Y.R.; Qin, Y.W.; Yuan, W.J.; et al. MicroRNAs are dynamically regulated in hypertrophic hearts, and miR-199a is essential for the maintenance of cell size in cardiomyocytes. J. Cell. Physiol. 2010, 225, 437-443. 
132. Rane, S.; He, M.; Sayed, D.; Vashistha, H.; Malhotra, A.; Sadoshima, J.; Vatner, D.E.; Vatner, S.F.; Abdellatif, M. Downregulation of miR-199a derepresses hypoxia-inducible factor- $1 \alpha$ and Sirtuin 1 and recapitulates hypoxia preconditioning in cardiac myocytes. Circ. Res. 2009, 104, 879-886.

133. Ikeda, S.; He, A.; Kong, S.W.; Lu, J.; Bejar, R.; Bodyak, N.; Lee, K.H.; Ma, Q.; Kang, P.M.; Golub, T.R.; et al. MicroRNA-1 negatively regulates expression of the hypertrophy-associated calmodulin and Mef2a genes. Mol. Cell Biol. 2009, 29, 2193-2204.

134. Zhang, Z.H.; Li, J.; Liu, B.R.; Luo, C.F.; Dong, Q.; Zhao, L.N.; Zhong, Y.; Chen, W.Y.; Chen, M.S.; Liu, S.M. MicroRNA-26 was decreased in rat cardiac hypertrophy model and may be a promising therapeutic target. J. Cardiovasc. Pharmacol. 2013, 62, 312-319.

135. Wang, J.; Song, Y.; Zhang, Y.; Xiao, H.; Sun, Q.; Hou, N.; Guo, S.; Wang, Y.; Fan, K.; Zhan, D.; et al. Cardiomyocyte overexpression of miR-27b induces cardiac hypertrophy and dysfunction in mice. Cell Res. 2012, 22, 516-527.

136. Boettger, T.; Beetz, N.; Kostin, S.; Schneider, J.; Kruger, M.; Hein, L.; Braun, T. Acquisition of the contractile phenotype by murine arterial smooth muscle cells depends on the Mir143/145 gene cluster. J. Clin. Investig. 2009, 119, 2634-2647.

137. Care, A.; Catalucci, D.; Felicetti, F.; Bonci, D.; Addario, A.; Gallo, P.; Bang, M.L.; Segnalini, P.; Gu, Y.; Dalton, N.D.; et al. MicroRNA-133 controls cardiac hypertrophy. Nat. Med. 2007, 13, 613-618.

138. Luo, X.; Xiao, J.; Lin, H.; Li, B.; Lu, Y.; Yang, B.; Wang, Z. Transcriptional activation by stimulating protein 1 and post-transcriptional repression by muscle-specific microRNAs of IKs-encoding genes and potential implications in regional heterogeneity of their expressions. J. Cell. Physiol. 2007, 212, 358-367.

139. Yin, V.P.; Lepilina, A.; Smith, A.; Poss, K.D. Regulation of zebrafish heart regeneration by miR-133. Dev. Biol. 2012, 365, 319-327.

140. Hu, S.; Huang, M.; Nguyen, P.K.; Gong, Y.; Li, Z.; Jia, F.; Lan, F.; Liu, J.; Nag, D.; Robbins, R.C.; et al. Novel microRNA prosurvival cocktail for improving engraftment and function of cardiac progenitor cell transplantation. Circulation 2011, 124, S27-S34.

141. Jakob, P.; Landmesser, U. Role of microRNAs in stem/progenitor cells and cardiovascular repair. Cardiovasc. Res. 2012, 93, 614-622.

(C) 2014 by the authors; licensee MDPI, Basel, Switzerland. This article is an open access article distributed under the terms and conditions of the Creative Commons Attribution license (http://creativecommons.org/licenses/by/3.0/). 